\title{
Optimization design and performance analysis of a miniature stirling engine
}

Zhanping You, Bo Yang, Lisheng Pan, and Changsheng Hao

Citation: AIP Conference Proceedings 1890, 040030 (2017);

View online: https://doi.org/10.1063/1.5005232

View Table of Contents: http://aip.scitation.org/toc/apc/1890/1

Published by the American Institute of Physics

\section{Articles you may be interested in}

A pistonless Stirling engine-The traveling wave heat engine

The Journal of the Acoustical Society of America 66, 1508 (1998); 10.1121/1.383505 


\title{
Optimization Design and Performance Analysis of a Miniature Stirling Engine
}

\author{
Zhanping You ${ }^{1, a)}$, Bo Yang ${ }^{1, b)}$, Lisheng Pan ${ }^{2, c)}$ and Changsheng Hao ${ }^{1, d)}$ \\ ${ }^{1}$ College of Mechanical Engineering Shijiazhuang Tiedao University, Shijiazhuang 050043, China; \\ ${ }^{2}$ Institute of mechanics, Chinese academy of sciences, Beijing 100190, China. \\ a) Corresponding author: youzhanping@163.com \\ b)819153750@qq.com \\ c)190756602@qq.com \\ d)47159083@qq.com
}

\begin{abstract}
Under given operation conditions, a stirling engine of $2 \mathrm{~kW}$ is designed which takes hydrogen as working medium. Through establishment of adiabatic model, the ways are achieved about performance improving. The ways are raising the temperature of hot terminal, lowering the temperature of cold end, increasing the average cycle pressure, speeding up the speed, phase angle being $90^{\circ}$, stroke volume ratio approximating to 1 and increasing the performance of regenerator.
\end{abstract}

Keywords: Miniature stirling engine, isothermal analysis, adiabatic analysis.

\section{INTRODUCTION}

Stirling engine belongs to external combustion, closed, reciprocating engine, so the heat source temperature is rather lower than that of common internal combustion engine. Forms of energy such as industrial high temperature flue gas, high temperature waste heat, biomass energy, solar energy, geothermal energy etc can be used as the driving energy the performances of stirling engine is studied by scholars at home and abroad ${ }^{[1-4]}$. These studies have significant roles on the performance optimization of stirling engine. In this article, the initial structure design of an $\alpha$-type stirling engine under given conditions is completed and the performance is studied.

\section{MINIATURE STIRLING ENGINE DESIGN}

The primary analysis and secondary analysis are the most common methods for performance studies of stirling engine. The primary analysis is isothermal analysis which is suitable for the calculation of power and efficiency, supposing that working substance is ideal gas and pressure is equal everywhere in the cavity. The secondary analysis method is also called adiabatic analysis method, which is usually used as the simulation method of the $\alpha$-type stirling engine.

\section{Structure Design}

An $\alpha$-type stirling engine mainly consists of expansion chamber, heater, regenerator, cooler and compression chamber. The structure parameters are shown in Table1. These structure parameters are verified by isothermal analysis and the effective and total power are within the specified range.

\footnotetext{
2nd International Conference on Materials Science, Resource and Environmental Engineering (MSREE 2017)

AIP Conf. Proc. 1890, 040030-1-040030-5; https://doi.org/10.1063/1.5005232

Published by AIP Publishing. 978-0-7354-1568-3/\$30.00
} 


\section{Initial Parameters}

Hydrogen is selected as working medium. The power is $2.0 \mathrm{~kW}$, the average cycle pressure is about $10.0 \mathrm{MPa}$, the rotate speed is about $3000 \mathrm{rpm}$. Usually, the temperature of working medium in heater is $80-120 \mathrm{~K}$ lower than that of the outside wall and the inner temperature of the cooler is $30-40 \mathrm{~K}$ higher than that of the outer wall surface of the cooler. The external wall temperature of the heater is setting as $1023 \mathrm{~K}$ and so the inner working temperature of which is $943 \mathrm{~K}$. The temperature of cooling water should not higher than $338 \mathrm{~K}$ and it is supposed as $318 \mathrm{~K}$ in this paper. So the inlet temperature is $293 \mathrm{~K}$. The wall surface temperature of cooler is approximately equal to the outlet temperature of the cooling water, namely the temperature is $318 \mathrm{~K}$. The internal temperature of the cooler is $348 \mathrm{~K}$.

TABLE 1. Structure Dimensions of the 2kW Stirling Engine.

\begin{tabular}{|c|c|c|c|c|c|}
\hline Content & Unit & Value & Content & Unit & Value \\
\hline Rotate speed & $\mathrm{rpm}$ & 3000 & Medium temperature in cooler & $\mathrm{K}$ & 348 \\
\hline Mean circulatory pressure & $\mathrm{MPa}$ & 10 & Useless volume in cooler & $\mathrm{m}^{3}$ & 0.000039 \\
\hline Engine efficiency & - & 0.4 & Inner diameter of the cooler & $\mathrm{m}$ & 0.001 \\
\hline Mole number of gas & $\mathrm{mol}$ & 0.691 & Length of cooler & $\mathrm{m}$ & 0.13 \\
\hline Heater outside wall temperature & $\mathrm{K}$ & 1023 & Useless volume in regenerator & $\mathrm{m}^{3}$ & 0.000106 \\
\hline Useless volume in heater & $\mathrm{m}^{3}$ & 0.0000105 & Validity of regenerator & - & 0.9924 \\
\hline Medium temperature in heater & $\mathrm{K}$ & 943 & Volumetric compression ratio & - & 1.7 \\
\hline Cooler outside wall temperature & $\mathrm{K}$ & 318 & Total useless volume & $\mathrm{m}^{3}$ & 0.000249 \\
\hline
\end{tabular}

\section{PERFORMANCE STUDIES OF THE MINIATURE STIRLING ENGINE}

The numerical studies of the stirling engine in determining the influencing factors is carried out by using adiabatic analysis.

\section{Effects of Tmperature on Performance}

The relationship between thermal end temperature with efficiency and power is shown in Fig. 1. It can be seen that the higher of the hot end temperature and the higher of the efficiency and output power when the cold end temperature is certain. When hot end temperature reaches $1200 \mathrm{~K}$, the efficiency can reach $42 \%$ and the power can reach $2330 \mathrm{~W}$. However, the surface temperature of the heater should be lower than $1270 \mathrm{~K}$, or it will reduce the life of the heater.

The relationship between cold end temperature with efficiency and power is shown in Fig. 2. It can be known that the cooler of the cooler and the higher of efficiency and output power. So it is a good way to improve performance by lowering the cold end temperature.

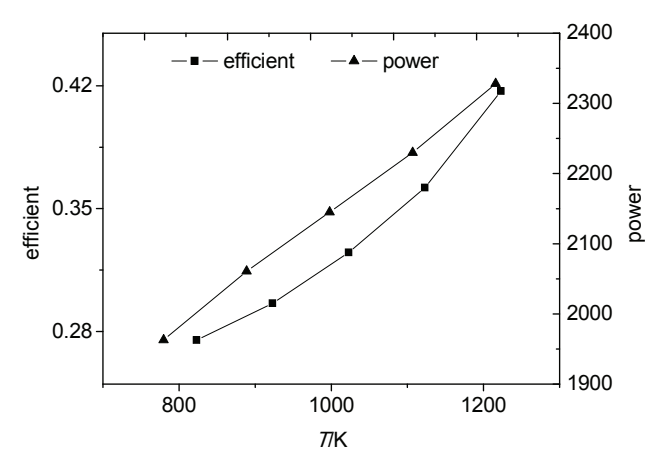

FIG. 1 Relationship between thermal end temperature with efficiency and power

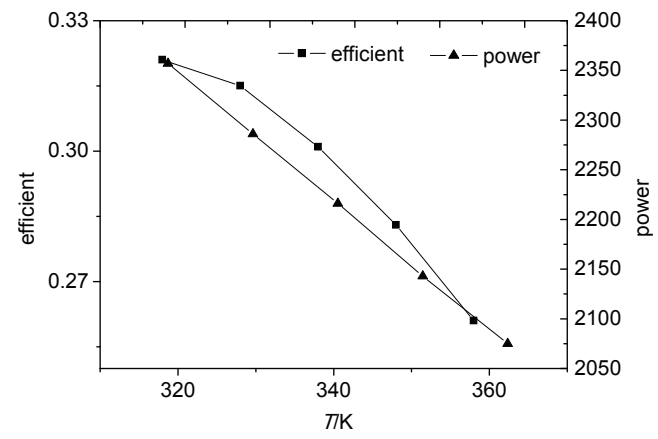

FIG. 2 Relationship between cold end temperature with efficiency and power 


\section{Effects of Pressure on Performance}

The relationship between efficiency and power with average cycle pressure is shown in Fig.3. As shown in Fig.3., thermal efficiency increases with the increasing of average cyclic pressure, so the engine's thermal efficiency can be improved through increasing the average cyclic pressure. However, the pressure should not exceed the maximum range. The average circulation pressure is generally confirmed by the maximum pressure of the cavities and heat exchangers.

\section{Effects of Rotate Speed on Performance}

The relationship between rotate speed with efficiency and power is shown in Fig.4. The thermal efficiency increases with the increasing of rotate speed in a certain range and then the tendency tends to slow down over a certain range. The power increases linearly with the rotate speed theoretically. However, the high speed can lead to the increasing of flow rate of working medium which causes a sharp rise in the flow resistance of the heat exchangers and reduces the engine performance and life.

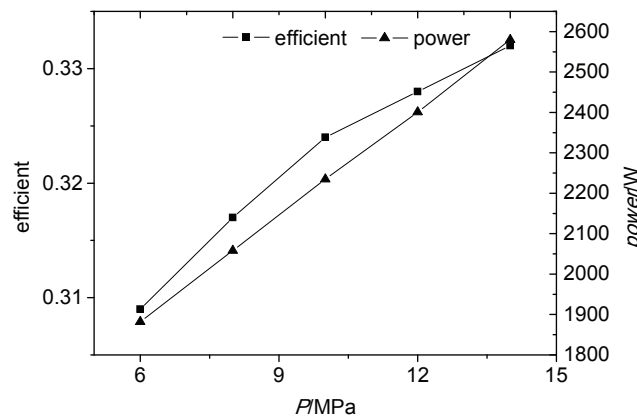

FIG.3 Relationship between average cyclic pressure with efficiency and power

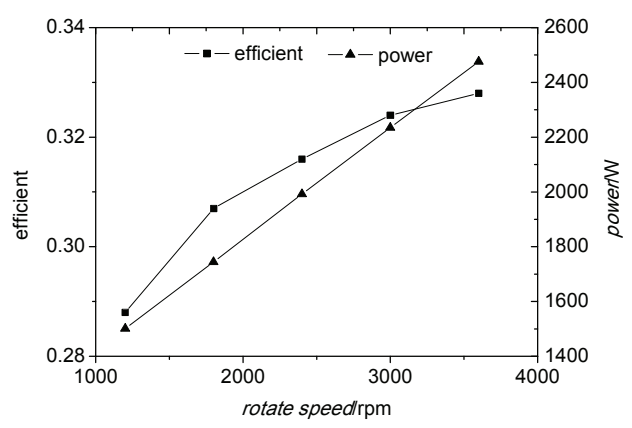

FIG. 4 Relation between rotate speed with efficiency and power

\section{Effects of Phase Angle on Efficiency}

The relationship between phase angle with efficiency is shown in fig.5. Different phase angle between expansion cavity with compression chamber will result different cycle efficiency. As approximate $90^{\circ}$ with maximum efficiency, so phase angle is usually affirmed as $90^{\circ}$.

\section{Effects of Regenerator Validity on Performance}

The relationship between the validity of regenerator with the power and efficiency is shown in Fig.6. The validity of the regenerator has a great effect on the power and efficiency. The higher of the regenerator validity and the greater of the output power and efficiency. Therefore, the power and efficiency of the stirling cycle can be improved by improving the validity of the regenerator. 


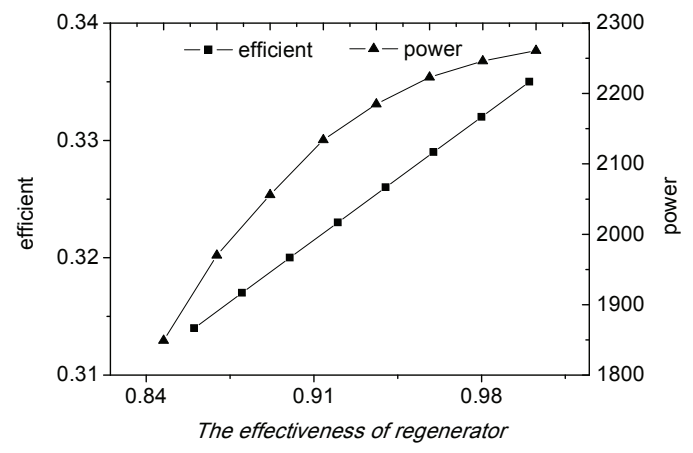

FIG. 5 Relationship between phase angle and efficiency

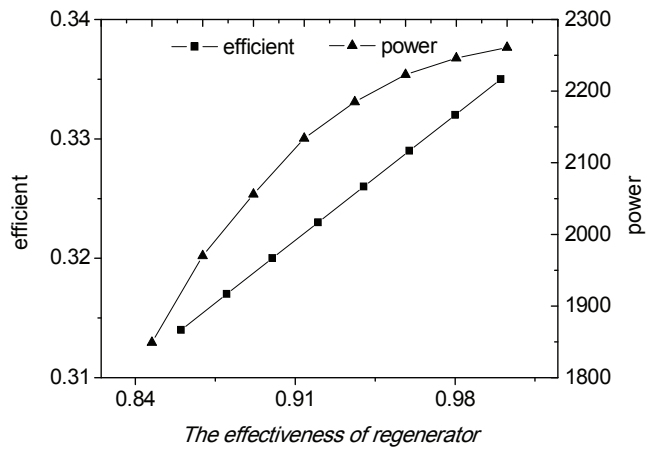

FIG. 6 Relationship between regenerator validity with efficiency and power

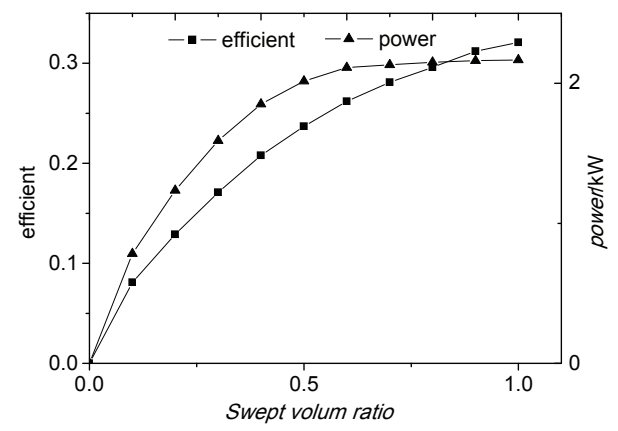

FIG. 7 Relationship between stroke volume ratio with efficiency and power

\section{Effects of Stroke Volume Ratio on Performance}

The relationship between stroke volume ratio with efficiency and power is shown in Figure.7. As the efficiency increases with the rise of stroke volume ratio. The maximum efficiency can be reached when stroke volume ratio is equal to 1 . So the trip volume of expansion cavity and compression cavity should be equal or close. The power also increases with the rise of stroke volume ratio and the trend gradually slows down. When the stroke volume ratio is between 0.5 to 1 , the power change is very small. Considering the above two factors, the stroke volume ratio should be 1 .

\section{CONCLUSION}

(1) Under a given operation condition, a $2 \mathrm{~kW}$ stirling engine is designed and the rationality of preliminary design is verified through isothermal analysis.

(2) The methods in improving the performances of stirling engine includes: improving the hot end temperature, reducing the cold end temperature, increasing the average cycle pressure, speeding up the rotate speed, phase angle approximately being equal to $90^{\circ}$ and stroke volume ratio approximately being equal to 1 , etc.

(3) The performance of regenerator has great effect on the performance of stirling engine, so it is an important content in regenerator product designing and optimization. 


\section{ACKNOWLEDGMENTS}

This work was financially supported by Hebei Natural Science Foundation (E2014210020) and Hebei Provincial Education Department Scientific Research Project (QN20131067) fund.

\section{REFERENCES}

1. CAMPOS M.C, MC Campus, Vargas et al, Thermodynamic optimization of a stirling engine, Engergy. 2012, 44 (1): 902-910.

2. Gianluca Valenti, Paolo Silva, Nicola Fergnani, et al, Experimental and numerical study of a micro-cogeneration stirling engine for residential applications, Energy Procedia. 2014, 45 (6): 1235-1244.

3. SOMAYEH TOGHYANI, ALIBAKHSH KASAEIAN, MOHAMMAD AHMADI H, et al, Multi-objective optimization of stirling engine using non-ideal adiabatic method, Energy Conversion and Management. 2014, 80 (1):54-62.

4. Li, T., Tang, D. W., Du, J.L. et al, Study on the change characteristics of the working medium stress transfer in stirling engine heat exchanger system, Journal of Engineering Thermophilic. 2012, 33 (11):1920-1923. 